\title{
ZSM-5 Filled Polyether Block Amide Membranes for Separating EA from Aqueous Solution by Pervaporation
}

\author{
Jin Gu, Xinran Zhang, Yunxiang Bai, Le Yang, Chunfang Zhang, and Yuping Sun \\ The Key Laboratory of Food Colloids and Biotechnology, Ministry of Education, School of Chemical and Material Engineering, \\ Jiangnan University, Wuxi 214122, China
}

Correspondence should be addressed to Yuping Sun; sunyp2003@yahoo.com.cn

Received 28 December 2012; Revised 25 March 2013; Accepted 9 April 2013

Academic Editor: Qian Yang

Copyright (C) 2013 Jin Gu et al. This is an open access article distributed under the Creative Commons Attribution License, which permits unrestricted use, distribution, and reproduction in any medium, provided the original work is properly cited.

ZSM-5 filled polyether block amide membranes (PEBA), PEBA/ZSM-5, were prepared and used to recover aroma, ethyl acetate (EA), from aqueous solution by pervaporation (PV). The membranes demonstrated high EA permselectivity, and with the increase of ZSM-5 loading, the separation factor increased initially and then decreased, while the total flux demonstrated the similar variation until the ZSM-5 loading was $10 \mathrm{wt} \%$, at which it reached the lowest value. After that, it began to increase again. On the other hand, the separation factor, and total flux of the PEBA/ZSM-5 membrane containing $10 \mathrm{wt} \%$ ZSM-5, PEBA/ZSM-5-10, increased with the increase of feed concentration and temperature. The best PV performance, separation factor and total flux of PEBA/ZSM-5-10 membrane were 185.5 and $199.5 \mathrm{gm}^{-2} \mathrm{~h}^{-1}$, respectively, with feed concentration of 5 wt $\%$ EA at $50^{\circ} \mathrm{C}$.

\section{Introduction}

Ethyl acetate (EA) is a very important chemical raw material, which is widely used in producing perfumes, plasticizers, varnishes, synthetic resins, and adhesive agents [1]. EA is mainly synthesized via a classical esterification process of acetic acid with ethanol in conventional industry [2, 3]. Due to the fact that the process of esterification is a reversible one, the high concentration can inhibit the reaction, so the product of the low concentration should be separated from water in time $[4,5]$. Distillation and pressure swing adsorption (PSA) were once the most common methods used to separate organic compounds from water. However, distillation is unsuitable for azeotropic mixtures, for separation of organic compounds in low concentration, or for thermally sensitive organic compounds [6]. PSA has the undesirable features of being energy intensive, with high investment cost and large installation area [7]. Compared with distillation and PSA, pervaporation (PV), as a new type of membrane separation technology, has obvious advantages in the field of gas separation and liquid separation in the separation of low concentration $[8,9]$. In this area, most of the research has focused on the preparation and modification of the membrane due to the fact that membrane materials are the core components in the process of pervaporation. To date, the materials that have been used for pervaporative recovering organic compounds from water were mainly hydrophobic, such as polydimethylsiloxane (PDMS) [10-14], polyurethaneurea (PU) $[15,16]$, poly(vinylidene fluoride-cohexafluoropropene) (P(VDF-co-HFP)) [17], ethylene-vinyl acetate (EVA) [18], and polyether block amide (PEBA) [19-21]. However, the trade off between permeability and selectivity is one of the biggest problems faced by pure polymer membranes, which greatly limits their further application in the chemical industries. In the past two decades, mixed matrix membranes started to emerge as an alternative approach in pervaporative membrane technology [22-25]. The PV performances as well as heat resistance were proved to be enhanced by incorporating inorganic fillers into polymer membranes. For the separation of organic compounds from aqueous solutions, hydrophobic inorganic fillers including zeolite [26-35], carbon black [36], carbon molecular sieve [37], and so on were adopted. Among them, zeolite with high $\mathrm{Si} / \mathrm{Al}$ ratio (ZSM-5) and silicalite (Al-free zeolite) is intensely investigated to remove different organic compounds from water due to its high hydrophobicity, surface area, and void volume, and uniform pore size distribution. For example, Kittur and coworkers [26] prepared ZSM-5/PDMS blend 
membranes for recovery of isopropanol from water. Their results showed that both permeation flux and selectivity increased simultaneously with the increase of zeolite content in the membrane matrix. The highest separation selectivity reached 80.84 and flux of $67.8 \mathrm{~g} / \mathrm{m}^{2} \mathrm{~h}$ at $30^{\circ} \mathrm{C}$ for $5 \mathrm{wt} \%$ of isopropanol in the feed when zeolite loading was $30 \mathrm{wt} \%$. Vane et al. [27] prepared ZSM-5 filled PDMS membranes and showed that the separation factor of ethanol from water increased monotonously from 8.7 to 43.1 when ZSM-5 loading increased from 0 to $65 \mathrm{wt} \%$, and the ethanol flux also increased from about 40 to $300 \mathrm{~g} / \mathrm{m}^{2} \mathrm{~h}$. Jia et al. [28] found that the incorporation of silicalite into PDMS enhanced both the total flux and acetic acid/water separation factor which were from 57 to $150 \mathrm{~g} / \mathrm{m}^{2} \mathrm{~h}$ and from 1.35 to 2.75 , respectively, with silicalite content of $49.9 \mathrm{wt} \%$. Nevertheless, inevitably nonselective voids are generated near the interface of polymer and inorganic particles due to their incompatibility. Attempts were made to enhance the compatibility between the fillers and polymers by introducing silane coupling agent [38], but chemical modifying the fillers will partially block their pores. So, it is probably more reasonable and convenient to enhance physical affinity between polymer segments and the inorganic fillers by selecting or synthesizing suitable polymer materials. PEBA is a block copolymer material, which could provide hydrophobic and flexible soft segments (polyether) for facilitating organic compounds diffusion and rigid hard segments (polyamide) for mechanical strength. So inorganic fillers should have good affinity to PEBA segments and are prone to be dispersed well in PEBA membrane because the polymer segments are amphiphilic.

In the present study, to enhance the PV performance of PEBA membrane, ZSM-5 filled PEBA membranes, PEBA/ZSM-5, were prepared, and their PV performance with different ZSM-5 loading, feed concentration, and temperature for recovering EA from aqueous solution was investigated. Furthermore, the PV performances with the increase of ZSM-5 loading were discussed from the viewpoint of the chemical and physical structures of PEBA/ZSM-5 membranes.

\section{Experimental}

2.1. Materials. Polyether block amide (PEBA) 2533 was obtained from Arkema Co. Ltd. (France). ZSM-5 zeolite with the average pore size of $0.55 \mathrm{~nm}$ was purchased from the Catalyst Plant of Nankai University (Tianjin, China). $n$ Butanol and EA were bought from Sinopharm Chemical Reagent Co. Ltd. (Shanghai, China).

2.2. Membrane Preparation. PEBA and ZSM-5 were accurately weighed and then added to $n$-butanol and transferred to a flask at $80^{\circ} \mathrm{C}$ with mechanical stirring for $4 \mathrm{~h}$ until a homogeneous solution was formed. The obtained solution was cast on a tetrafluoroethylene plate with a dry scraper. The solutions with ZSM-5 loading of $0,5,10,20$, and 40 wt $\%$ (the weight ratio of ZSM-5 to PEBA) were evaporated at room temperature for $24 \mathrm{~h}$ in the air. The formed membranes were designated as PEBA, PEBA/ZSM-5-5, PEBA/ZSM-5-10, PEBA/ZSM-5-20, and PEBA/ZSM-5-40, respectively.

2.3. FT-IR Measurement. The samples of ZSM-5, PEBA, PEBA/ZSM-5-10, and PEBA/ZSM-5-40 for FT-IR measurement were prepared by painting a thin layer of casting solution on a potassium bromide flake and evaporated the solvent at room temperature. Then, the samples were characterized by a FTLA2000-type Fourier transform infrared (FT-IR) spectrometer.

2.4. TGA Measurement. Thermal stability of ZSM-5, PEBA, PEBA/ZSM-5-10, and PEBA/ZSM-5-40 was examined with a METTLER 1/1100SF Thermogravimetric Analyzer (TGA) from $30^{\circ} \mathrm{C}$ to $800^{\circ} \mathrm{C}$ with a heating rate of $10^{\circ} \mathrm{C} / \mathrm{min}$ and a nitrogen flow of $50 \mathrm{~mL} / \mathrm{min}$.

2.5. Scanning Electron Microscopy. Scanning electron micrographs of ZSM-5, PEBA, PEBA/ZSM-5-10, and PEBA/ZSM5-40 were performed on a Hitachi S4800 scanning electron microscope (SEM) instrument. All the samples were coated with a thin layer of gold to prevent charging.

2.6. Mechanical Properties Studies. Tensile tests on the membranes of PEBA, PEBA/ZSM-5-5, PEBA/ZSM-5-10, PEBA/ZSM-5-20, and PEBA/ZSM-5-40 were carried out at room temperature using an electronic universal testing machine (Shenzhen, China) with a crosshead speed of $30 \mathrm{~mm} / \mathrm{min}$. The width and length of the sample were $10 \mathrm{~mm}$ and $50 \mathrm{~mm}$. The membranes were evaluated by two parameters as shown in the following equations:

$$
\begin{gathered}
\sigma=\frac{F}{b d}, \\
E=\frac{\sigma}{\Delta L / L},
\end{gathered}
$$

where $\sigma$ is the tensile stress, $F$ is the maximum load, $b$, and $d$ represent the width and thickness of the samples, respectively. $E$ represents young's modulus, and $\Delta L$ and $L$ are the extension and the original length.

2.7. Static Contact Angle Measurement. Static contact angles for water of PEBA/ZSM-5 membranes were measured by sessile drop method [39] using a contact angle meter (OCA 20, Dataphysics Instruments $\mathrm{GmbH}$ Germany) at $25^{\circ} \mathrm{C}$ and about $65 \%$ relative humidity. The volume of the water drop used was always $2 \mathrm{~mL}$. All reported values were the average of at least eight measurements taken at different locations of the film surface and had a typical mean error of $1^{\circ}$.

2.8. Degree of Swelling Measurement. The dried PEBA/ZSM5 membranes were immersed in different concentration of EA aqueous solution at $30^{\circ} \mathrm{C}$ at the same time, respectively. At regular intervals, the swollen membranes were wiped out carefully with tissue paper to remove superficial liquid and weighted in a tightly closed bottle. The degree of swelling (DS) 
of the membrane was then determined from the following equation:

$$
\mathrm{DS}=\frac{m_{s}-m_{o}}{m_{o}} \times 100 \%,
$$

where $m_{o}$ and $m_{s}$ are the weights of dry and swollen membranes, respectively.

2.9. Determination of Diffusion Coefficient. The diffusion coefficient was estimated to describe the diffusion behavior of the system. The diffusion coefficient of component $i$ was calculated from (3) as previously reported by Ma et al. [40] and evolved from Fick's law of (4) when assuming that the concentration profile along the diffusion length $x$ is linear:

$$
\begin{gathered}
D_{i}=\frac{J_{i} \delta}{C_{i}}, \\
J_{i}=-D_{i} \frac{d C_{i}}{d x},
\end{gathered}
$$

where $D_{i}$ represents concentration-averaged diffusion coefficient of component $i\left(\mathrm{~m}^{2} / \mathrm{s}\right), J_{i}$ is the flux of component $i, C_{i}$ is the concentration $\left(\mathrm{kg} / \mathrm{m}^{3}\right), \delta$ is the membrane thickness, and $x$ is the diffusion length (m).

2.10. PV Experiments. The PV experiment setup and procedure were the same as those described previously [41]. The membrane was installed in the testing cell, and the effective area was $35.24 \mathrm{~cm}^{2}$. The feed solution was continuously circulated from a feed tank to the upstream side of the membrane by a pump. The downstream pressure was kept at $200 \pm 10 \mathrm{kPa}$, and the penetrant was collected in a cold trap. The compositions of the feed and the penetrant were measured using GC900 gas chromatography equipped with a thermal conductivity detector (TCD). The permeation flux $(J)$ and the separation factor $(\alpha)$ for all membranes were calculated according to the following equation:

$$
\begin{aligned}
J & =\frac{Q}{A t}, \\
\alpha_{\mathrm{EA} / \text { water }} & =\frac{Y_{\mathrm{EA}} / Y_{\text {water }}}{X_{\mathrm{EA}} / X_{\text {water }}},
\end{aligned}
$$

where $Q$ is the weight of permeate collected in time $t$, and $A$ is the effective membrane area, and $X$ and $Y$ represent the mass fractions of the organic in the feed and permeate, respectively.

\section{Results and Discussion}

\subsection{Membrane Characterization}

3.1.1. FT-IR Analysis. Figure 1 shows the FT-IR spectra of ZSM-5, PEBA, PEBA/ZSM-5-10, and PEBA/ZSM-5-40. As shown from the spectra of ZSM-5 in Figure 1(a), a distinct absorption band appeared at around $1100 \mathrm{~cm}^{-1}$ assigning to $\mathrm{Si}-\mathrm{O}$. The peak at around $800 \mathrm{~cm}^{-1}$ represented the stretching

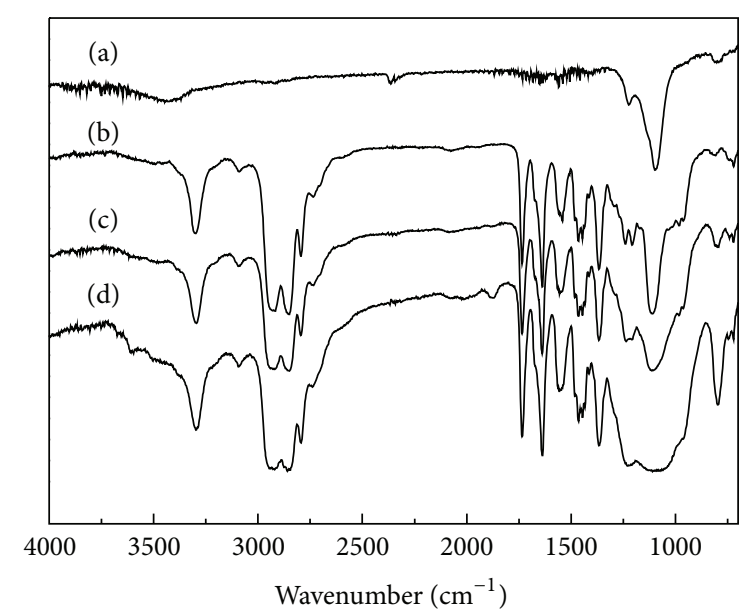

FIGURE 1: FT-IR spectra of (a) ZSM-5, (b) PEBA, (c) PEBA/ZSM-510, and (d) PEBA/ZSM-5-40.

vibrations of $\mathrm{Al}-\mathrm{O}$, which was weaker than that of $\mathrm{Si}-\mathrm{O}$ due to the fact that the ratio of $\mathrm{Si} / \mathrm{Al}$ was high. In Figure 1(b), the adsorptions observed at $3302 \mathrm{~cm}^{-1}$ and $1680 \mathrm{~cm}^{-1}$ correspond to the stretching vibration peak of $\mathrm{NH}, \mathrm{C}=\mathrm{O}$ indicating the presence of a polyamide group. The peak located at $1300 \mathrm{~cm}^{-1}$ was the stretching vibration of C-O corresponding to polyether groups. As can be seen from Figures 1(c) and 1(d), after the addition of ZSM-5 particles, no new absorption peak could be observed except for $\mathrm{Si}-\mathrm{O}$ peak, suggesting that ZSM-5 particles were physically blended within the polymer matrix.

3.1.2. TGA Analysis. The thermal decomposition curves of PEBA/ZSM-5 membranes were shown in Figure 2. In Figure 2(a), the ZSM-5 had an obvious thermal weight loss from $30^{\circ} \mathrm{C}$ to $200^{\circ} \mathrm{C}$, mainly due to the loss of water molecules attached to the ZSM-5. Besides, the ZSM-5 presented a total weight loss about $3 \%$ from $30^{\circ} \mathrm{C}$ to $800^{\circ} \mathrm{C}$, indicating that the ZSM-5 was stable at high temperature. It could be seen from Figure 2(b) that PEBA, PEBA/ZSM-5-10, and PEBA/ZSM5-40 had an apparent thermogravimetric interval. Below $300^{\circ} \mathrm{C}$, the sample presented a thermal weight loss at around $2 \%$, mainly due to the loss of crystal water and solvent volatilization, while the membrane itself was stable without thermal decomposition. From $300^{\circ} \mathrm{C}$ to $500^{\circ} \mathrm{C}$, the hot weight loss of the PEBA, PEBA/ZSM-5-10, and PEBA/ZSM-5-40 was $95.4 \%, 87.0 \%$, and $67.9 \%$, respectively. That means that the weight loss of PEBA, PEBA/ZSM-5-10, and PEBA/ZSM-540 membrane decreased and the decomposition temperature increased with the increasing loading of ZSM-5, indicating that the incorporation of ZSM-5 improved the thermal stability of PEBA/ZSM-5 membranes.

3.1.3. SEM Analysis. Figure 3 showed the scanning electron micrographs of ZSM-5 particles and the cross-section of PEBA, PEBA/ZSM-5-10, and PEBA/ZSM-5-40 membranes. As can be seen from Figure 3(a), ZSM-5 zeolite as a rectangular parallelepiped block particles was about $3 \sim 5 \mu \mathrm{m}$. 


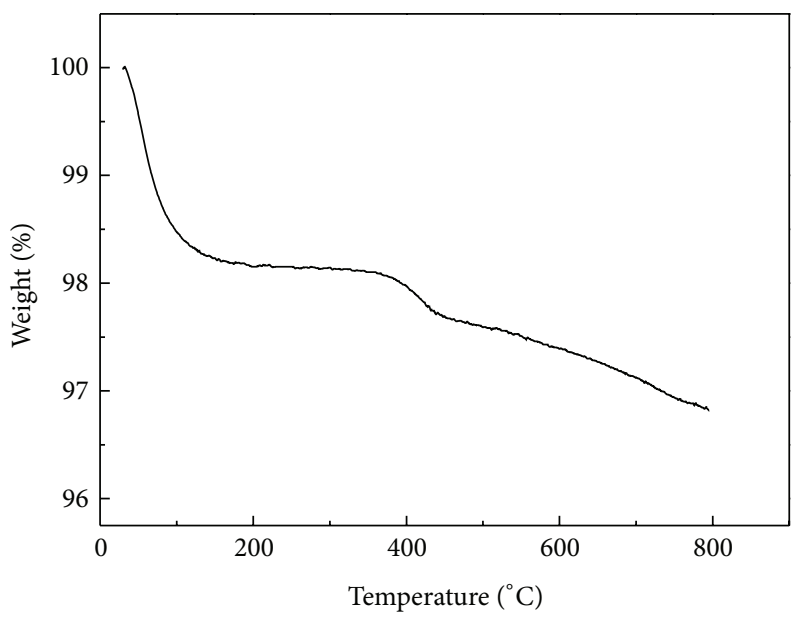

(a)

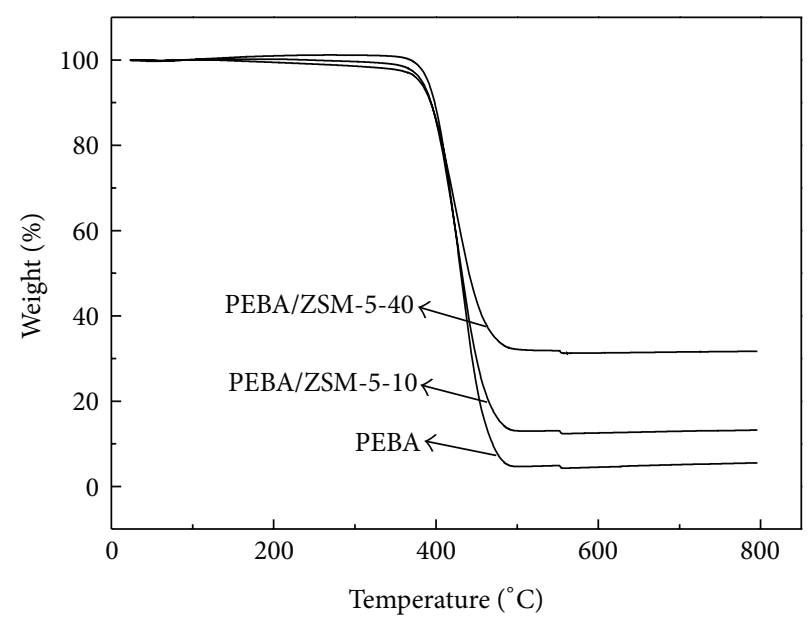

(b)

FIgUre 2: TGA plots of (a) ZSM-5 and (b) PEBA/ZSM-5.

From Figure 3(b) to Figure 3(f), no appreciable pore could be observed, indicating that defect-free dense membrane was synthesized. It could be seen from Figure 3(c) to Figure 3(f) that ZSM-5 particles were uniformly dispersed in the membrane matrix.

3.1.4. Mechanical Properties. Figure 4 described the effect of ZSM-5 content on the mechanical properties of PEBA/ZSM5 membranes. From Figure 4, the tensile strength of PEBA/ZSM-5 membranes, which is the maximum stress value of uniform plastic deformation of material under tensile stress, decreased with the increase of ZSM-5 loading because the addition of inorganic particles reduced the elasticity of membrane. As shown in Figure 4, the Young's modulus of PEBA/ZSM-5 membranes, which is a physical quantity to describe the solid material to resist deformation, increased correspondingly with the increase of ZSM-5 loading due to the increased rigidity of PEBA/ZSM-5 chains.

3.1.5. Contact Angle. Figure 5 shows the effect of ZSM5 loading on the contact angle for water of PEBA/ZSM-5 membranes. As can be seen from Figure 5, the contact angle for water of PEBA/ZSM-5 membranes increased with the increase of ZSM-5 loading. Obviously, the hydrophobicity of PEBA/ZSM-5 membranes was enhanced with the increase of ZSM-5 loading because that the zeolite ZSM-5 shows good hydrophobicity. But after the amount of ZSM-5 is up to $40 \%$, the hydrophobicity of PEBA/ZSM-5 membranes substantially keeps constant with the increase of ZSM-5 loading, that means that the surface of PEBA membrane has a certain capacity of ZSM-5, and ZSM-5 will enter the interior of the membrane when the amount of ZSM-5 is increased to a certain degree.

3.2. Effect of ZSM-5 Loading on Membrane Swelling. The equilibrium DS values of PEBA/ZSM-5 membranes in pure water, pure EA, and EA/water mixtures with different EA concentration at $30^{\circ} \mathrm{C}$ were shown in Figure 6 . It could be seen that the DS values of PEBA/ZSM-5 membranes decreased in pure EA and EA aqueous solutions, while nearly unchanged in pure water, with the increase of ZSM-5 loading. It may be explained that the incorporation of ZSM-5 decreased the mobility of the PEBA chains and blocked the free movement of EA and water molecular into PEBA/ZSM-5 membranes. From Figure 6, it could also be seen that the DS values of PEBA/ZSM-5 membranes increased with the increase of EA concentration, suggesting that the PEBA/ZSM-5 membranes had preferential selective adsorption for EA.

\subsection{Effect of ZSM-5 Loading on PV Performance of PEBA/} ZSM-5 Membranes. Figure 7 shows the variation of separation factor and permeation flux as a function of ZSM-5 loading in the PEBA/ZSM- 5 membranes with $5 \mathrm{wt} \%$ of EA in feed at $30^{\circ} \mathrm{C}$. As shown in Figure 7, the flux decreased initially and then increased with the increase of ZSM-5 loading, and when the ZSM-5 loading was $10 \mathrm{wt} \%$, the flux reached the lowest value, while the separation factor increased initially and then decreased with the increase of ZSM-5 loading, and when the ZSM-5 loading was $10 \mathrm{wt} \%$, the separation factor was the highest. The increase of separation factor of PEBA/ZSM5 membranes with the increase of ZSM-5 loading from 0 to $10 \mathrm{wt} \%$ is mainly due to the increasing hydrophobicity of membrane after adding ZSM-5. But when ZSM-5 loading was more than $10 \mathrm{wt} \%$, the separation factor began to decrease as it could be attributed to the aggregation of ZSM-5 particles and the increasing defect between polymer chains and ZSM5 which allowed EA and water to permeate simultaneously.

3.4. Effect of Feed Concentration on PV Performance of PEBA/ZSM-5-10 Membrane. The effect of feed concentration on PV performance of PEBA/ZSM-5-10 membrane was studied at $30^{\circ} \mathrm{C}$. The relationship among the permeation flux 


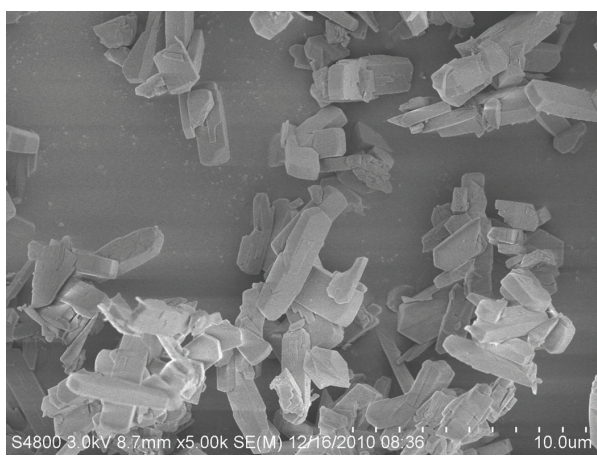

(a)

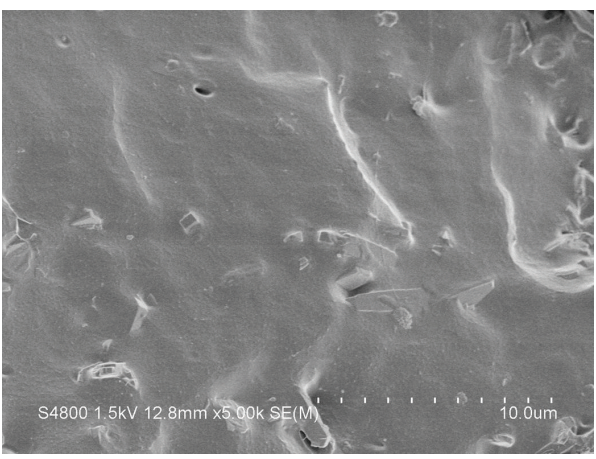

(c)

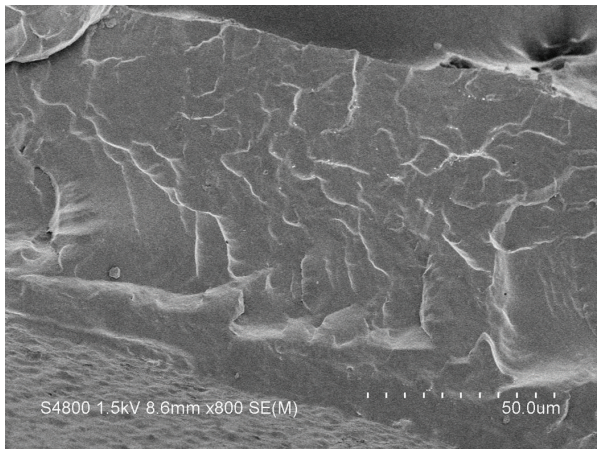

(e)

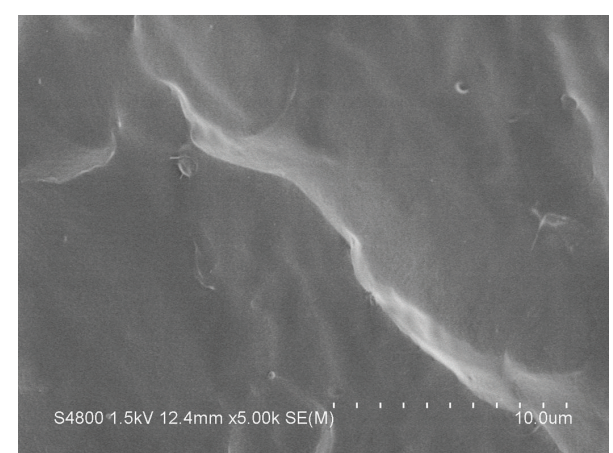

(b)

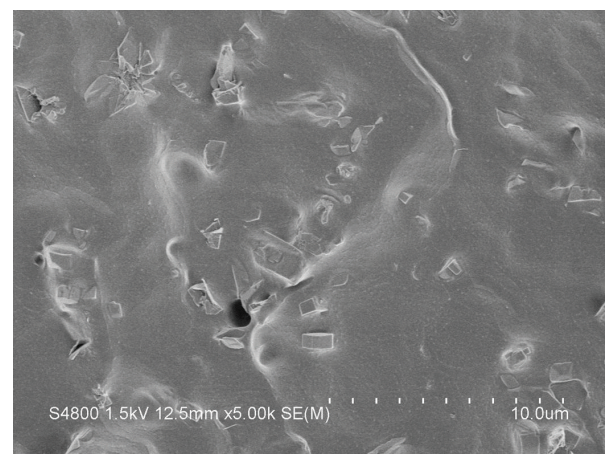

(d)

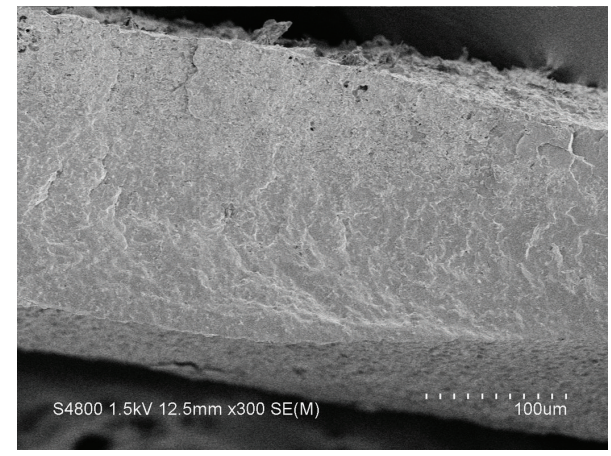

(f)

FIGURE 3: SEM images of ZSM-5 particles and the cross-section of membranes, (a) ZSM-5 particles, (b) pure PEBA, (c) PEBA/ZSM-5-10 (d) PEBA/ZSM-5-40, and (e) and (f) are the whole cross-sectional images of PEBA and PEBA/ZSM-5-40 membrane, respectively.

and liquid and vapor phase concentrations follows (6) for recovery of VOC from aqueous solution [42]:

$$
J_{i}=K_{i} \rho\left[\left(C_{i}\right)^{L}-\left(C_{i}\right)^{V}\right]
$$

where $K_{i}(\mathrm{~m} / \mathrm{s}), q\left(\mathrm{~mol} / \mathrm{m}^{3}\right),\left(C_{i}\right)^{L}$ (dimensionless), and $\left(C_{i}\right)^{V}$ (dimensionless) are the overall mass transfer rate coefficient, total molar density of feed, bulk liquid phase concentration (mole fraction), and bulk vapor phase concentration (mole fraction, reported as an equivalent liquid phase mole fraction), respectively, for component $i$. The increase of feed concentration is nearly equal to the increase of the driving force $\left(C_{i}\right)^{L}$ because $\left(C_{i}\right)^{V}$ is usually small and can be neglected. Therefore, the permeation flux increased usually with an increase of feed concentration. In this study, water flux decreased slightly from 59.58 to $26.26 \mathrm{~g} / \mathrm{m}^{2} \mathrm{~h}$, and EA flux increased from 41.87 to $140.8 \mathrm{~g} / \mathrm{m}^{2} \mathrm{~h}$ when the feed concentration increased from 1 to $5 \mathrm{wt} \%$ as can be seen from Figure $8(\mathrm{~b})$. This is because the driving force of EA was enhanced and that of water nearly depressed or unchanged with the increase of feed concentration. Uragami et al. [43] proved that organic molecules mainly permeated through the hydrophobic phase of a polymer membrane containing microphase structure, while water molecules mainly permeated through hydrophilic matrix. For PEBA membranes, the hydrophobic and prevalent polyether segments formed the main matrix of the whole membrane, and the low content of polar hard segments was dispersed evenly in the polyether matrix. The soft segments of polyether, which have the strong affinity to EA, provide a path for the permeation of EA. 


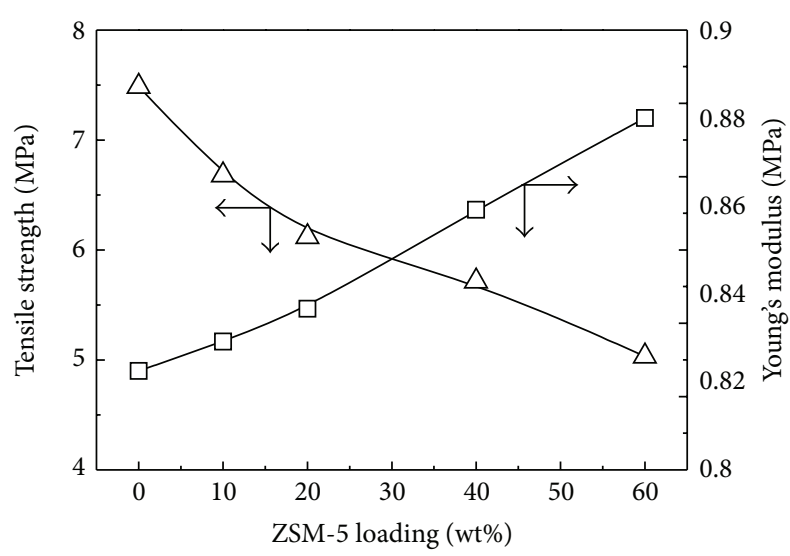

FIgURE 4: Tensile strength and Young's modulus of PEBA/ZSM-5 membranes with different ZSM-5 loading.

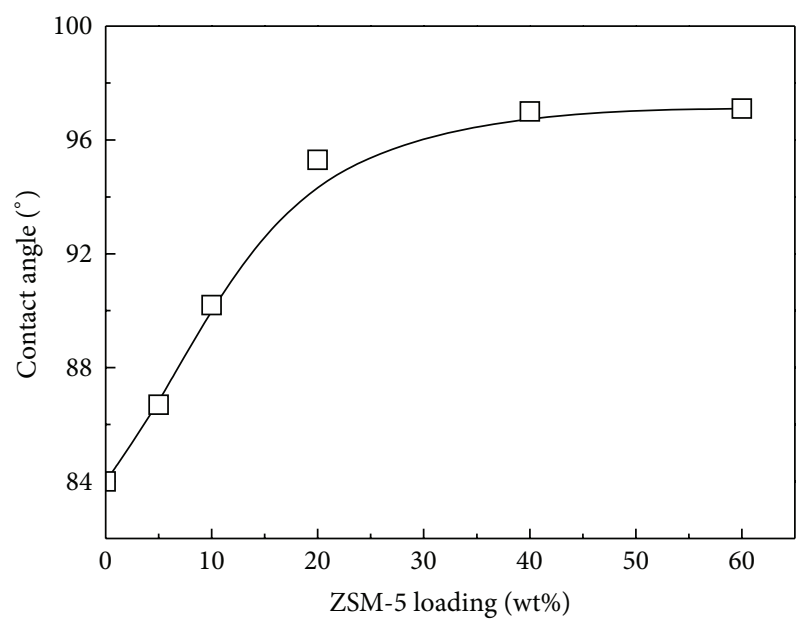

FIGURE 5: Effect of ZSM-5 loading on the contact angle of PEBA/ZSM-5 membranes.

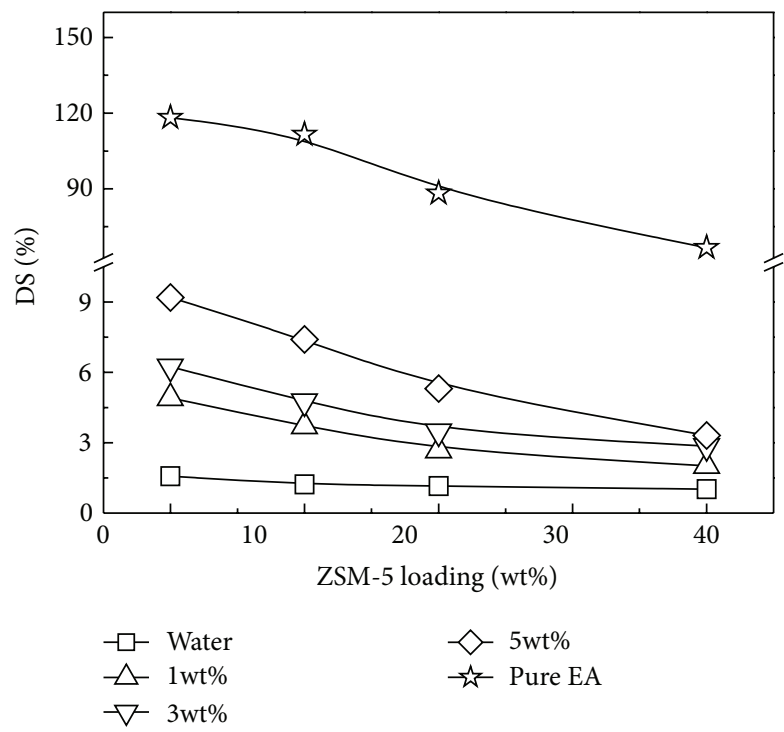

FIGURE 6: Effect of ZSM-5 loading and feed concentration on the equilibrium DS of PEBA/ZSM-5 membranes at $30^{\circ} \mathrm{C}$.

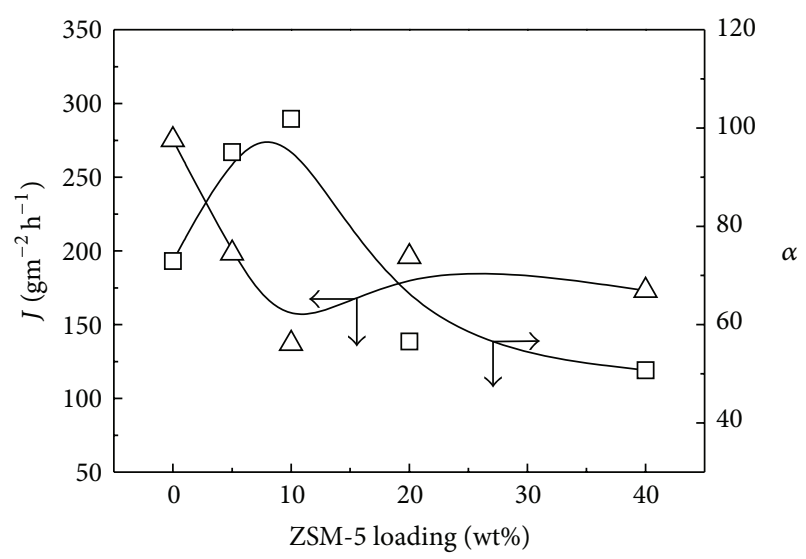

Figure 7: Effect of ZSM-5 loading on PV performance of PEBA/ZSM-5 membranes: separation factor and permeation flux (EA concentration in feed, $5 \mathrm{wt} \%$, feed temperature, $30^{\circ} \mathrm{C}$ ).

But the diffusion of water became very difficult because the low content of hard and polar segments of polyamide could not form a continuous phase in the PEBA membrane. In addition, in the studied feed concentration range, the mild DS of PEBA/ZSM-5-10 membrane, from $3.7 \%$ to $7.4 \%$ seen from Figure 6, will also be resistant to water permeation.

3.5. Effect of Operating Temperature on PV Performance of PEBA/ZSM-5-10 Membrane. Figure 9 shows the variation of the separation factor $\alpha$ and total flux of PEBA/ZSM5-10 membrane with feed temperature. From Figure 9, it can be seen that both $\alpha$ and total flux increased with the increase of the feed temperature below $50^{\circ} \mathrm{C}$. Commonly, the separation factor decreases with the increase of feed temperature in PV process. This anomalous phenomenon can be explained that the mass transfer driving force through the membrane increased at a higher temperature and the activity of the polymer chains increased, so the resistance of penetration component in the membrane was reduced. This could result in the increase of the total flux and the EA flux. Therefore, the separation factor increased. But when the temperature is higher than $50^{\circ} \mathrm{C}$, the increasing swelling allowed EA and water to permeate simultaneously, resulting in the decrease of the separation factor. Generally, the relationship among the permeation flux and the operating temperature for recovery of VOC from aqueous solution follows the Arrhenius relationship, as shown in the following equation:

$$
J_{i}=J_{o} \exp \left(\frac{-E_{a}}{\mathrm{RT}}\right)
$$

where $J_{i}$ is the flux $\left(\mathrm{gm}^{-2} \mathrm{~h}^{-1}\right)$ of the component $i, J_{o}$ is a constant $\left(\mathrm{gm}^{-2} \mathrm{~h}^{-1}\right), E_{a}$ is the activation energy $\left(\mathrm{Jmol}^{-1}\right), R$ is the gas constant $\left(\mathrm{Jmol}^{-1} \mathrm{~K}^{-1}\right)$, and $T$ is the absolute temperature $(\mathrm{K})$.

Figure 10 shows the Arrhenius relationship between the flux and permeation activation energy. From Figure 10, the permeation activation energy of $\mathrm{EA}\left(E_{a \mathrm{EA}}=19.74 \mathrm{~kJ} / \mathrm{mol}\right)$ 


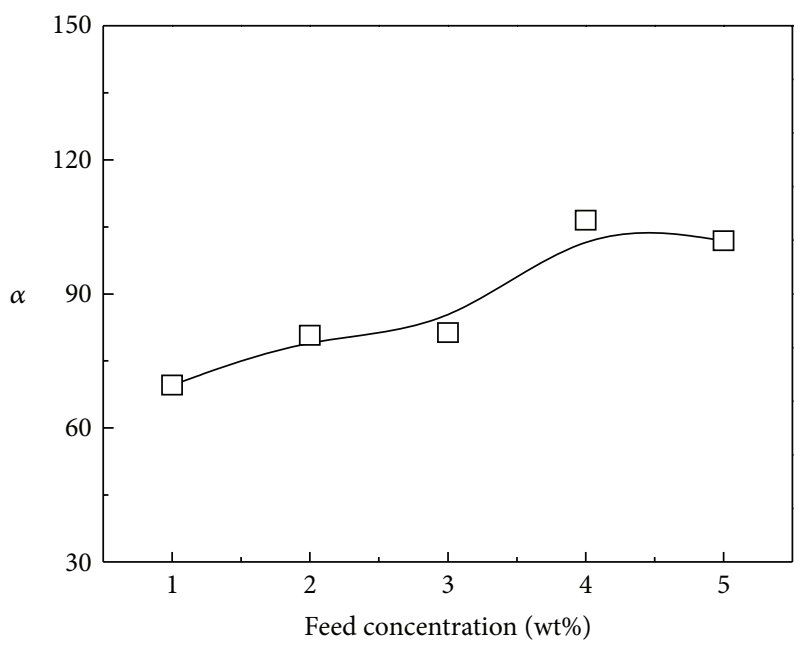

(a)

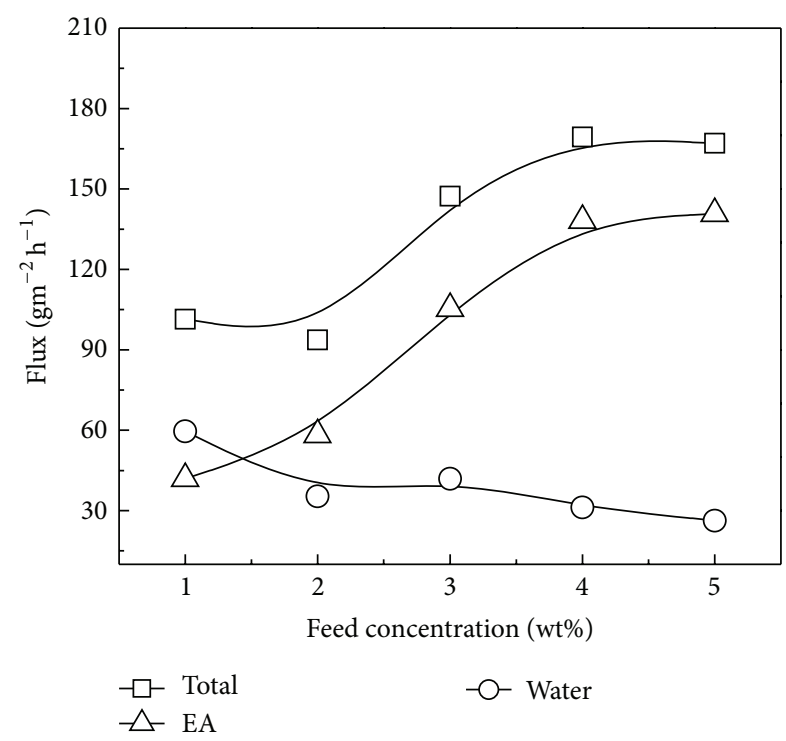

(b)

FIGURE 8: Effect of feed concentration on PV performance of PEBA/ZSM-5-10 membrane at $30^{\circ} \mathrm{C}$ : (a) separation factor and (b) permeation flux.

was higher than that of water $\left(E_{a \text { water }}=7.62 \mathrm{~kJ} / \mathrm{mol}\right)$ for the PEBA/ZSM-5-10 membrane. The value of the activation energy reflects the sensitivity of permeate flux to temperature. The larger permeation activation energy of EA implies that EA permeation flux is more sensitive to the increase of temperature compared to that of water. Consequently, the permeate flux of EA increased greater than the water molecules with the increase of temperature, which is corresponding to the increased separation factor. But when the temperature is higher than $50^{\circ} \mathrm{C}$, EA and water pass through the membrane at the same time due to the intensification of the segment movement, so the separation factor decreased.

3.6. Diffusion Coefficient. The average diffusion coefficient of EA and water through the PEBA/ZSM-5-10 membrane in
TABLE 1: Diffusion coefficients of EA and water through PEBA/ZSM5 membranes with different ZSM-5 loading.

\begin{tabular}{lccccc}
\hline & \multicolumn{5}{c}{ ZSM-5 loading (wt\%) } \\
& 0 & 5 & 10 & 20 & 40 \\
\hline$D_{\text {EA }}\left(10^{10} \mathrm{~m}^{2} \mathrm{~s}^{-1}\right)$ & 2.16 & 1.99 & 1.18 & 1.56 & 1.33 \\
$D_{\text {water }}\left(10^{12} \mathrm{~m}^{2} \mathrm{~s}^{-1}\right)$ & 2.98 & 2.09 & 1.16 & 2.77 & 2.56 \\
\hline
\end{tabular}

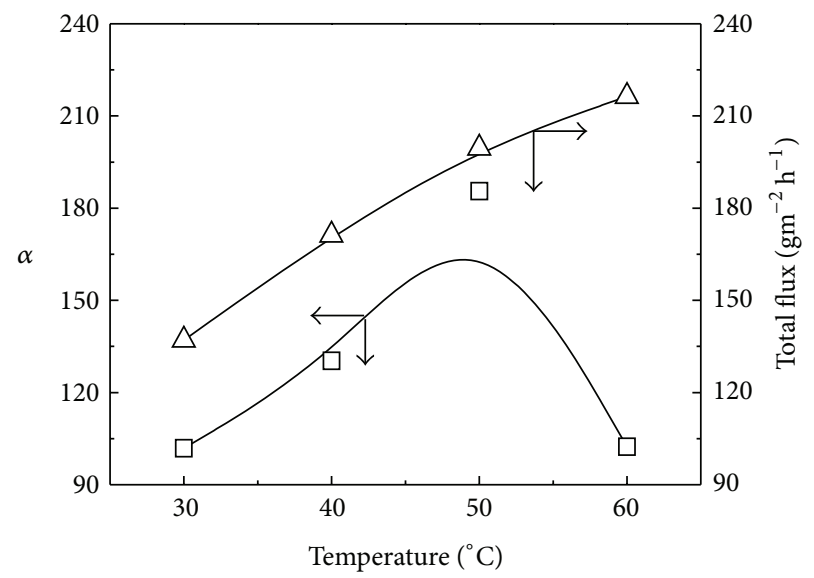

FIGURE 9: Effect of operating temperature on PV performance of PEBA-ZSM-5-10 membrane: separation factor and permeation flux (EA concentration in feed, $5 \mathrm{wt} \%$ ).

the feed concentration of $5 \mathrm{wt} \%$ at $30^{\circ} \mathrm{C}$ calculated by (3), the results are shown in Table 1. Overall, the diffusion coefficient of EA is 100 times higher than that of water molecules which implies that the membrane material is conducive to the diffusion of the EA.

3.7. PV Performance for Separating EA/Water Mixtures with the Literatures. Table 2 compares the PV performance for separating EA/water mixtures with the literatures. The PEBA/ZSM-5-10 membrane in this study exhibited the highest EA normalized flux (defined as the EA flux multiplied by the membrane thickness) though the separation factor is not outstanding enough compared to other membrane materials.

\section{Conclusions}

Defect-free ZSM-5 filled polyether block amide membranes, PEBA/ZSM-5, were prepared for the separation of EA from its aqueous solutions by pervaporation. The chemical structure, morphology, and thermal stability of these filled membranes were characterized. It could be seen that ZSM- 5 dispersed uniformly in the membrane. With the incorporation of ZSM5 in the membrane, the thermal stability of the membrane increased, while the swelling degree decreased. The separation factor increased first and then decreased with the increase of the ZSM-5 loading. The diffusion coefficient of EA was much larger than that of water for the PEBA/ZSM5 membranes, indicating that the membranes were highly 
TABLE 2: Comparison of PV results of PEBA/ZSM-5-10 membrane for EA/water mixture with the literatures.

\begin{tabular}{|c|c|c|c|c|c|}
\hline Ref. & Membrane & $W(\mathrm{EA}) / \%$ & $T\left({ }^{\circ} \mathrm{C}\right)$ & $J\left(\mathrm{~kg} \mu \mathrm{m} / \mathrm{m}^{2} \cdot \mathrm{h}\right)$ & $\alpha$ (EA/water) \\
\hline [13] & PDMS-1070 & 0.05 & 50 & 3.5 & 524 \\
\hline$[14]$ & PDMS/PTFE & 0.99 & 30 & 6.7 & 95 \\
\hline$[16]$ & Cross-linked polyurethaneurea & 2.5 & 30 & 25 & 655 \\
\hline$[17]$ & $\mathrm{P}(\mathrm{VDF}-\mathrm{co}-\mathrm{HFP})$ & 5 & 30 & 28 & 175 \\
\hline$[18]$ & EVA-38 & 2.5 & 30 & 11 & 118 \\
\hline [19] & PEBA & 8.3 & 30 & 26 & 73 \\
\hline This work & PEBA/ZSM-5-10 & 5 & 30 & 40 & 102 \\
\hline
\end{tabular}

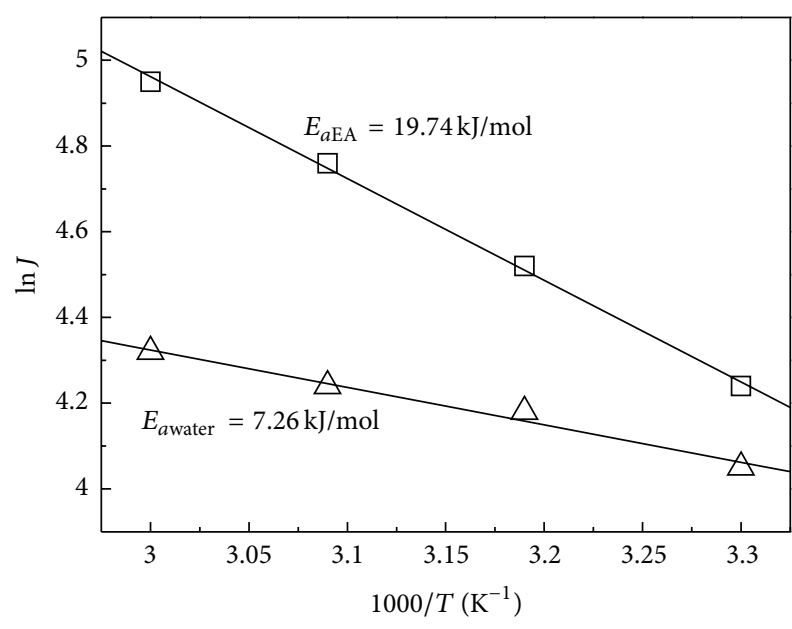

$\square$ EA

$\triangle$ Water

Figure 10: Arrhenius plots of PEBA/ZSM-5-10 membrane.

EA permselective. The PEBA/ZSM-5 membranes containing 10 wt\% ZSM-5, that is, PEBA/ZSM-5-10, showed the highest separation factor at $30^{\circ} \mathrm{C}$. With the increase of the operating temperature and feed concentration, both the permeation flux and separation factor increased except when the temperature exceeded $50^{\circ} \mathrm{C}$. The best PV performance, separation factor, and total flux of the PEBA/ZSM-5 membranes containing $10 \mathrm{wt} \%$ ZSM-5 were 185.5 and $199.5 \mathrm{gm}^{-2} \mathrm{~h}^{-1}$, respectively, with feed concentration of $5 \mathrm{wt} \% \mathrm{EA}$ at $50^{\circ} \mathrm{C}$.

\section{Conflict of Interests}

"Arkema Co. Ltd." and "Sinopharm Chemical Reagent Co. Ltd." are two companies from wich the authors purchased chemical reagents. There is no conflict of interest in this paper.

\section{Acknowledgments}

This research was financially supported by the National Natural Science Foundation of China (Grant no. 21106053), the Fundamental Research Funds for the Central Universities (JUSRP311A01), and the Industry-Academia Cooperation Innovation Fund Projects of Jiangsu Province (BY2012058).

\section{References}

[1] H. K. Yuan, J. Ren, X. H. Ma, and Z. L. Xu, "Dehydration of ethyl acetate aqueous solution by pervaporation using PVA/PAN hollow fiber composite membrane," Desalination, vol. 280, no. 1-3, pp. 252-258, 2011.

[2] E. Y. Kenig, H. Bäder, A. Górak, B. Beßling, T. Adrian, and H. Schoenmakers, "Investigation of ethyl acetate reactive distillation process," Chemical Engineering Science, vol. 56, no. 21-22, pp. 6185-6193, 2001.

[3] Y. T. Tang, Y. W. Chen, H. P. Huang, C. C. Yu, S. B. Hung, and M. J. Lee, "Design of reactive distillations for acetic acid esterification," AIChE Journal, vol. 51, no. 6, pp. 1683-1699, 2005.

[4] S. G. Adoor, L. S. Manjeshwar, S. D. Bhat, and T. M. Aminabhavi, "Aluminum-rich zeolite beta incorporated sodium alginate mixed matrix membranes for pervaporation dehydration and esterification of ethanol and acetic acid," Journal of Membrane Science, vol. 318, no. 1-2, pp. 233-246, 2008.

[5] S. D. Bhat and T. M. Aminabhavi, "Pervaporation-aided dehydration and esterification of acetic acid with ethanol using 4A zeolite-filled cross-linked sodium alginate-mixed matrix membranes," Journal of Applied Polymer Science, vol. 113, no. 1, pp. 157-168, 2009.

[6] D. H. Park, N. Nishiyama, Y. Egashira, and K. Ueyama, "Separation of organic/water mixtures with silylated MCM-48 silica membranes," Microporous and Mesoporous Materials, vol. 66, no. 1, pp. 69-76, 2003.

[7] S. Araki, S. Imasaka, S. Tanaka, and Y. Miyake, "Pervaporation of organic/water mixtures with hydrophobic silica membranes functionalized by phenyl groups," Journal of Membrane Science, vol. 380, no. 1-2, pp. 41-47, 2011.

[8] P. Shao and R. Y. M. Huang, "Polymeric membrane pervaporation," Journal of Membrane Science, vol. 287, no. 2, pp. 162-179, 2007.

[9] D. Anjali Devi, K. V. S. N. Raju, and T. M. Aminabhavi, "Synthesis and characterization of moisture-cured polyurethane membranes and their applications in pervaporation separation of ethyl acetate/water azeotrope at $30^{\circ} \mathrm{C}$," Journal of Applied Polymer Science, vol. 103, no. 5, pp. 3405-3414, 2007.

[10] A. Aroujalian and A. Raisi, "Recovery of volatile aroma components from orange juice by pervaporation," Journal of Membrane Science, vol. 303, no. 1-2, pp. 154-161, 2007.

[11] V. García, N. Diban, D. Gorri, R. Keiski, A. Urtiaga, and I. Ortiz, "Separation and concentration of bilberry impact aroma compound from dilute model solution by pervaporation," Journal of Chemical Technology and Biotechnology, vol. 83, no. 7, pp. 973-982, 2008. 
[12] A. Isci, S. Sahin, and G. Sumnu, "Recovery of strawberry aroma compound by pervaporation," Journal of Food Engineering, vol. 75, no. 1, pp. 36-42, 2006.

[13] A. Baudot and M. Marin, "Improved recovery of an ester flavor compound by pervaporation coupled with a flash condensation," Industrial and Engineering Chemistry Research, vol. 38, no. 11, pp. 4458-4469, 1999.

[14] W. D. Zhang, W. Sun, J. Yang, and Z. Q. Ren, "The study on pervaporation behaviors of dilute organic solution through PDMS/PTFE composite membrane," Applied Biochemistry and Biotechnology, vol. 160, no. 1, pp. 156-167, 2010.

[15] Y. X. Bai, J. W. Qian, J. Yin, Z. B. Zhai, and Y. Yang, "HTPBbased polyurethaneurea membranes for recovery of aroma compounds from aqueous solution by pervaporation," Journal of Applied Polymer Science, vol. 104, no. 1, pp. 552-559, 2007.

[16] Y. Bai, J. Qian, C. Zhang, L. Zhang, Q. An, and H. Chen, "Crosslinked HTPB-based polyurethaneurea membranes for recovery of ethyl acetate from aqueous solution by pervaporation," Journal of Membrane Science, vol. 325, no. 2, pp. 932-939, 2008.

[17] B. K. Zhu, X. Z. Tian, and Y. Y. Xu, "Recovering ethyl acetate from aqueous solution using $\mathrm{P}(\mathrm{VDF}-\mathrm{co}-\mathrm{HFP})$ membrane based pervaporation," Desalination, vol. 184, no. 1-3, pp. 71-78, 2005.

[18] Y. Bai, J. Qian, Q. An, Z. Zhu, and P. Zhang, "Pervaporation characteristics of ethylene-vinyl acetate copolymer membranes with different composition for recovery of ethyl acetate from aqueous solution," Journal of Membrane Science, vol. 305, no. 1-2, pp. 152-159, 2007.

[19] M. K. Djebbar, Q. T. Nguyen, R. Clément, and Y. Germain, "Pervaporation of aqueous ester solutions through hydrophobic poly(ether-block-amide) copolymer membranes," Journal of Membrane Science, vol. 146, no. 1, pp. 125-133, 1998.

[20] R. Jiraratananon, P. Sampranpiboon, D. Uttapap, and R. Y. M. Huang, "Pervaporation separation and mass transport of ethylbutanoate solution by polyether block amide (PEBA) membranes," Journal of Membrane Science, vol. 210, no. 2, pp. 389-409, 2002.

[21] P. Sampranpiboon, R. Jiraratananon, D. Uttapap, X. Feng, and R. Y. M. Huang, "Pervaporation separation of ethyl butyrate and isopropanol with polyether block amide (PEBA) membranes," Journal of Membrane Science, vol. 173, no. 1, pp. 53-59, 2000.

[22] S. D. Bhat and T. M. Aminabhavi, "Novel sodium alginate composite membranes incorporated with SBA-15 molecular sieves for the pervaporation dehydration of aqueous mixtures of isopropanol and 1,4-dioxane at $30^{\circ} \mathrm{C}, "$ Microporous and Mesoporous Materials, vol. 91, no. 1-3, pp. 206-214, 2006.

[23] S. D. Bhat, B. V. K. Naidu, G. V. Shanbhag, S. B. Halligudi, M. Sairam, and T. M. Aminabhavi, "Mesoporous molecular sieve (MCM-41)-filled sodium alginate hybrid nanocomposite membranes for pervaporation separation of water-isopropanol mixtures," Separation and Purification Technology, vol. 49, no. 1, pp. 56-63, 2006.

[24] B. V. K. Naidu, S. D. Bhat, M. Sairam et al., "Comparison of the pervaporation separation of a water-acetonitrile mixture with zeolite-filled sodium alginate and poly(vinyl alcohol)-polyaniline semi-interpenetrating polymer network membranes," Journal of Applied Polymer Science, vol. 96, no. 5, pp. 1968-1978, 2005.

[25] S. D. Bhat and T. M. Aminabhavi, "Zeolite K-LTL-loaded sodium alginate mixed matrix membranes for pervaporation dehydration of aqueous-organic mixtures," Journal of Membrane Science, vol. 306, no. 1-2, pp. 173-185, 2007.
[26] A. A. Kittur, S. K. Choudhari, and M. Y. Kariduraganavar, "Preparation of zeolite-incorporated PDMS membranes for pervaporation separation of isopropanol-water mixtures," Composite Interfaces, vol. 13, no. 4-6, pp. 507-521, 2006.

[27] L. M. Vane, V. V. Namboodiri, and T. C. Bowen, "Hydrophobic zeolite-silicone rubber mixed matrix membranes for ethanolwater separation: effect of zeolite and silicone component selection on pervaporation performance," Journal of Membrane Science, vol. 308, no. 1-2, pp. 230-241, 2008.

[28] M. D. Jia, K. V. Peinemann, and R. D. Behling, "Preparation and characterization of thin-film zeolite-PDMS composite membranes," Journal of Membrane Science, vol. 73, no. 2-3, pp. 119128, 1992.

[29] I. F. J. Vankelecom, D. Depre, S. De Beukelaer, and J. B. Uytterhoeven, "Influence of zeolites in PDMS membranes. Pervaporation of water/alcohol mixtures," The Journal of Physical Chemistry, vol. 99, no. 35, pp. 13193-13197, 1995.

[30] H. Yang, Q. T. Nguyen, Z. Ping, Y. Long, and Y. Hirata, "Desorption and pervaporation properties of zeolite-filled poly(dimethylsiloxane) membranes," Materials Research Innovations, vol. 5, no. 2, pp. 101-106, 2001.

[31] S. Y. Lu, C. P. Chiu, and H. Y. Huang, "Pervaporation of acetic acid/water mixtures through silicalite filled polydimethylsiloxane membranes," Journal of Membrane Science, vol. 176, no. 2, pp. 159-167, 2000.

[32] C. Dotremont, B. Brabants, K. Geeroms, J. Mewis, and C. Vandecasteele, "Sorption and diffusion of chlorinated hydrocarbons in silicalite-filled PDMS membranes," Journal of Membrane Science, vol. 104, no. 1-2, pp. 109-117, 1995.

[33] M. V. Chandak, Y. S. Lin, W. Ji, and R. J. Higgins, "Sorption and diffusion of VOCs in DAY zeolite and silicalite-filled PDMS membranes," Journal of Membrane Science, vol. 133, no. 2, pp. 231-243, 1997.

[34] E. A. Fouad and X. Feng, "Pervaporative separation of nbutanol from dilute aqueous solutions using silicalite-filled poly (dimethyl siloxane) membranes," Journal of Membrane Science, vol. 339, no. 1-2, pp. 120-125, 2009.

[35] A. Dobrak, A. Figoli, S. Chovau et al., "Performance of PDMS membranes in pervaporation: effect of silicalite fillers and comparison with SBS membranes," Journal of Colloid and Interface Science, vol. 346, no. 1, pp. 254-264, 2010.

[36] D. Panek and K. Konieczny, "Preparation and applying the membranes with carbon black to pervaporation of toluene from the diluted aqueous solutions," Separation and Purification Technology, vol. 57, no. 3, pp. 507-512, 2007.

[37] F. Peng, Z. Jiang, C. Hu, Y. Wang, H. Xu, and J. Liu, "Removing benzene from aqueous solution using CMS-filled PDMS pervaporation membranes," Separation and Purification Technology, vol. 48, no. 3, pp. 229-234, 2006.

[38] S. Yi, Y. Su, and Y. Wan, "Preparation and characterization of vinyltriethoxysilane (VTES) modified silicalite-1/PDMS hybrid pervaporation membrane and its application in ethanol separation from dilute aqueous solution," Journal of Membrane Science, vol. 360, no. 1-2, pp. 341-351, 2010.

[39] O. N. Tretinnikov, "Selective accumulation of functional groups at the film surfaces of stereoregular poly(methyl methacrylate)s," Langmuir, vol. 13, no. 11, pp. 2988-2992, 1997.

[40] X. Ma, C. Hu, R. Guo, X. Fang, H. Wu, and Z. Jiang, "HZSM5filled cellulose acetate membranes for pervaporation separation of methanol/MTBE mixtures," Separation and Purification Technology, vol. 59, no. 1, pp. 34-42, 2008. 
[41] C. F. Zhang, L. Yang, Y. X. Bai, J. Gu, and Y. P. Sun, “ZSM-5 filled polyurethaneurea membranes for pervaporation separation isopropyl acetate from aqueous solution," Separation and Purification Technology, vol. 85, pp. 8-16, 2012.

[42] G. A. Polotskaya, A. V. Penkova, A. M. Toikka, Z. Pientka, L. Brozova, and M. Bleha, "Transport of small molecules through polyphenylene oxide membranes modified by fullerene," Separation Science and Technology, vol. 42, no. 2, pp. 333-347, 2007.

[43] T. Uragami, T. Meotoiwa, and T. Miyata, "Effects of the addition of calixarene to microphase-separated membranes for the removal of volatile organic compounds from dilute aqueous solutions," Macromolecules, vol. 34, no. 19, pp. 6806-6811, 2001. 

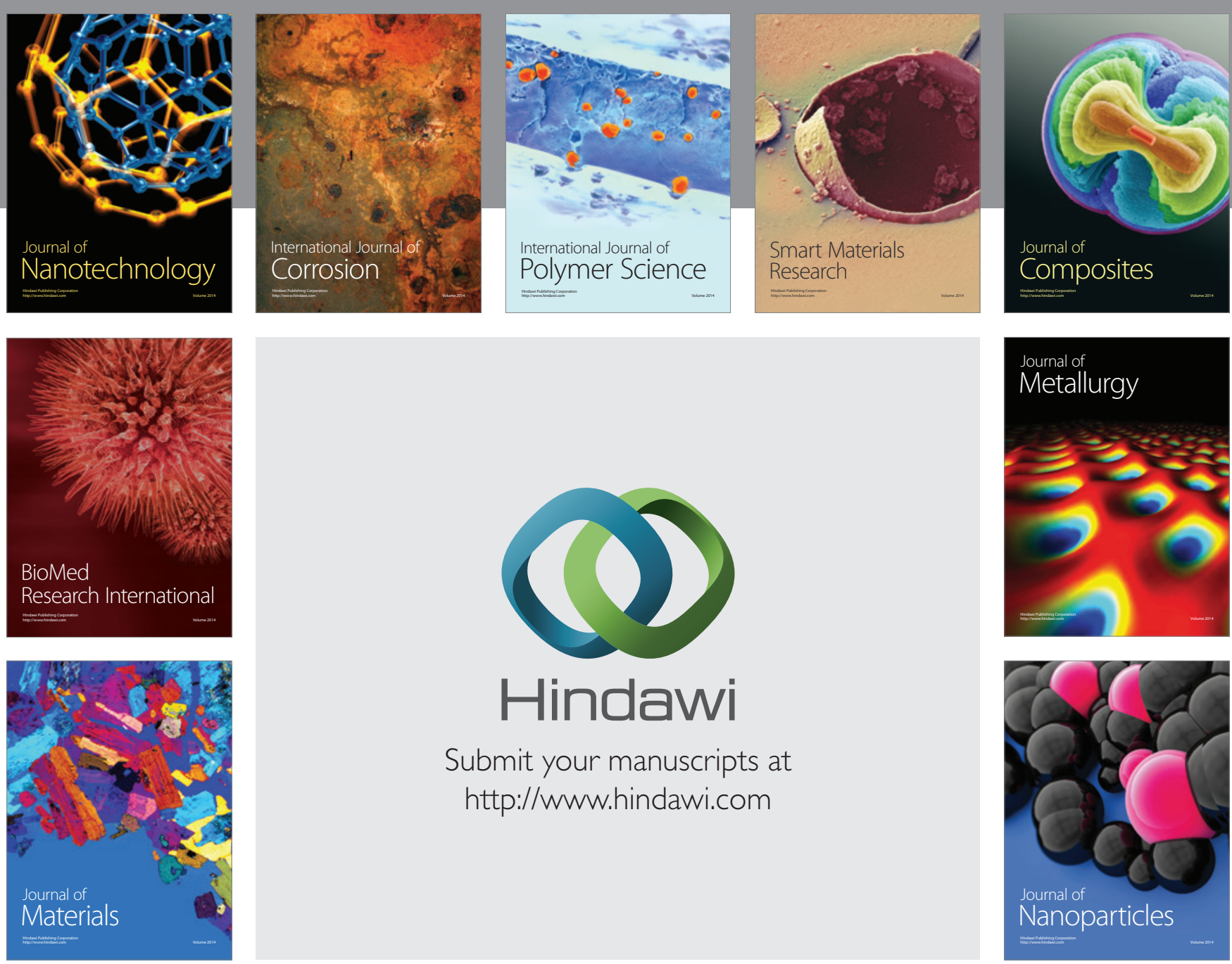

Submit your manuscripts at http://www.hindawi.com
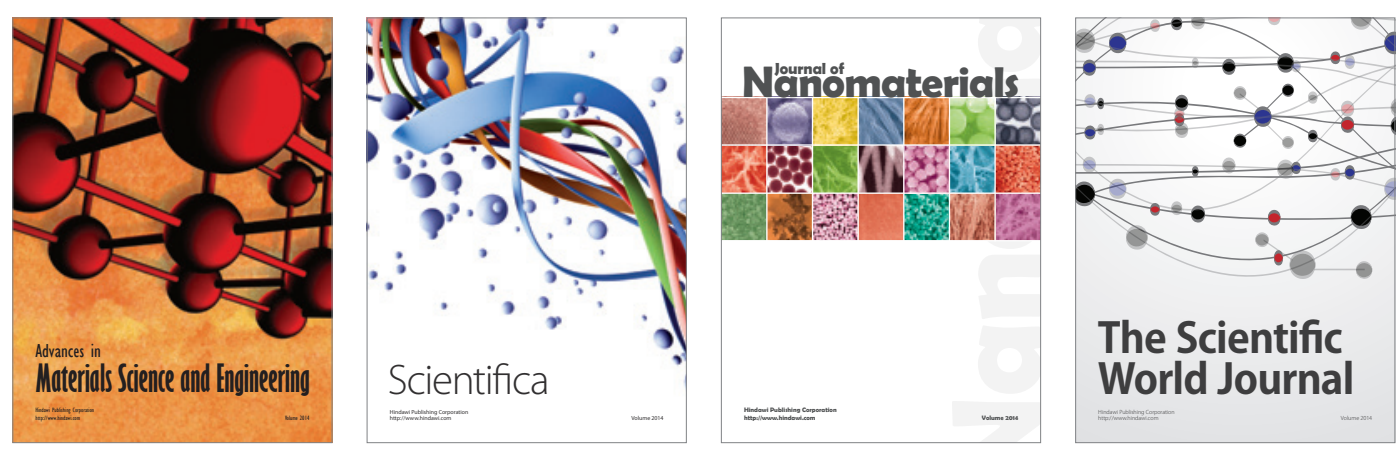

\section{The Scientific World Journal}
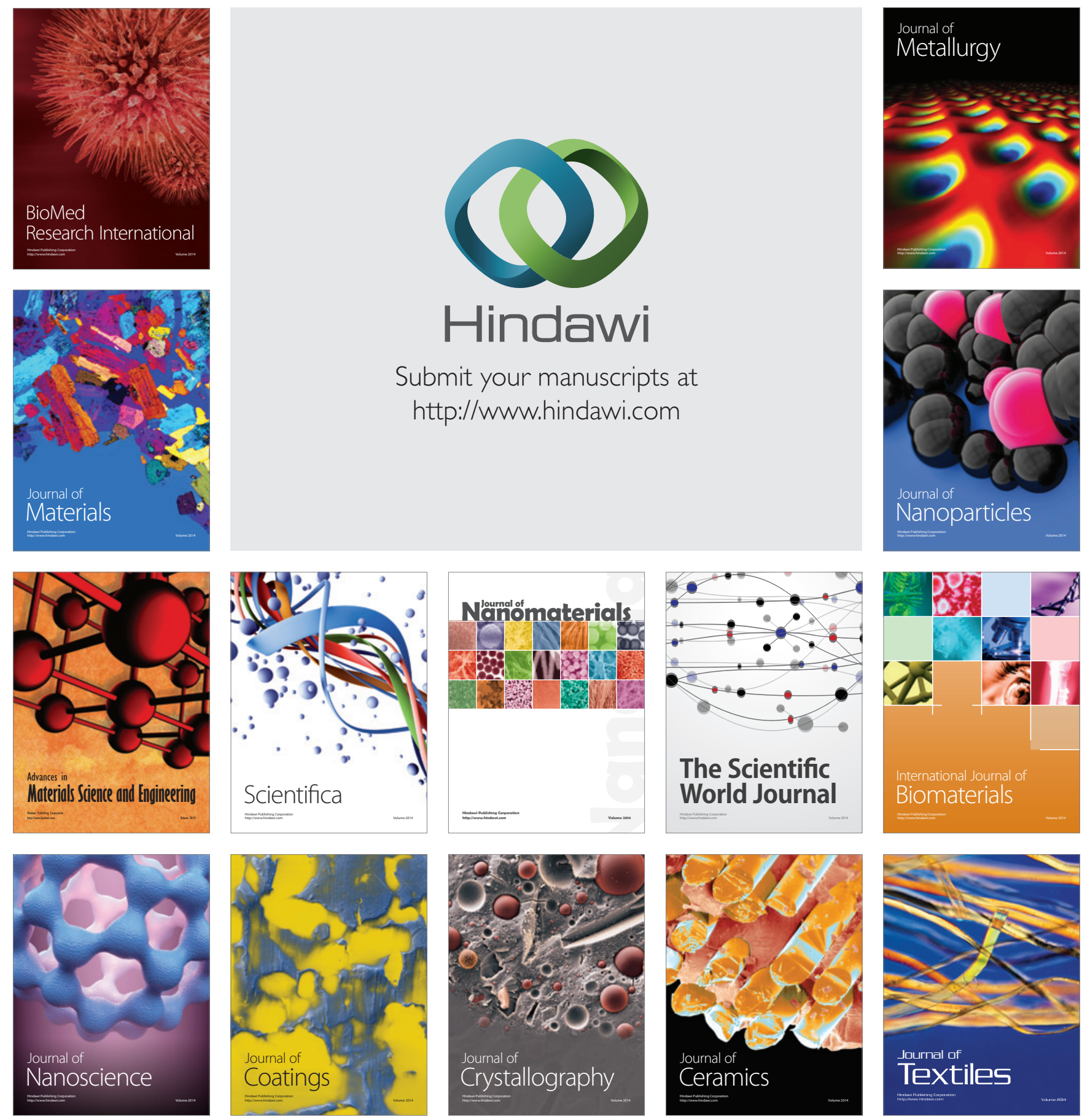